\title{
Outsourcing as a means to improve the efficiency of activity of machinery enterprises
}

\author{
Vyacheslav Zheleznov ${ }^{1}$, Tatyana Volkova $^{2}$, Maria Volkova $^{3}$ \\ ${ }^{1}$ Postgraduate, Bauman University, Moscow; \\ ${ }^{2}$ Senior lecturer, Bauman University, Moscow; \\ ${ }^{3}$ Associate Professor, PhD, Bauman University, Moscow.
}

\begin{abstract}
The article shows the relevance of outsourcing repair services at machine-building enterprises in conditions of high wear of equipment, the decline in the organization of management of technical and repair services and the effectiveness of this activity. The positive and negative sides of outsourcing, as well as factors for evaluating the effectiveness of the transfer of repair functions to outsourcing are given.

Keywords: organization of production, maintenance, repair services, outsourcing.
\end{abstract}

\section{Introduction}

Dynamic changes in the state of enterprises make it necessary to periodically review and assess the conformity of organizational structures for managing the maintenance and repair of equipment to the needs of the main production. An analysis of practical experience in the functioning of repair management systems in Russia shows that for industrial enterprises, depending on current resources, environmental conditions, the structure of production links, and also other factors, various types of organizational management structures may be effective $[1,2,3]$. Therefore, it is necessary to establish factors that have a significant impact on the formation of organizational structures for the management of units for maintenance, repair of equipment at enterprises, and bring them into the system.

Studying the economic condition of enterprises and their ability to compete, it is important to study the issues of possible restructuring and outsourcing of non-core functions. This issue is quite deeply studied by foreign scientists [4]. Note that scientists in Russia are also seriously trying to consider this topic [5]. However, questions about how outsourcing can save resources of enterprises or other business entities remain little studied in Russia. It is equally important to know how to ensure controllability of repair and maintenance costs; reduction of staff, and hence the cost of its maintenance; increase in equipment productivity; reduction of the risk of breakage after repairs; improving the quality and reliability of technological equipment; short deadlines. Below, we will present methods and algorithms that improve the economic and technical indicators of the repair management and organization system that exists in most Russian industrial enterprises. 


\section{Methods and materials. Organization of a technical system service and repairs at Russian enterprises}

There are no generalized studies on the system of maintenance and repair at the enterprises of the Russian Federation. Nevertheless, the system of organization and management of repairs existing at most Russian industrial enterprises, according to the authors, can be represented as follows: a chief engineer, to whom the functional departments of the chief mechanic, chief power engineer, production automation, etc., heads it. These functional units oversee the process of organizing repair maintenance of fixed assets of all production structural units of the enterprise and act both as customers and as direct executors of repair work. The strategy of preventive maintenance (PM) maintenance and repair (maintenance and repair) is used. This system of organization of repair services (RS) has the following disadvantages:

1. The single function of monitoring the maintenance and production of fixed assets is divided between several contractors, which weakens the control force, because of which the quality of the product suffers.

2. One functional performs two conflicting tasks. He issues an order for the performance of work and directly produces the corresponding work. With this approach, it is impossible to achieve an optimal output result.

3. There is a need to bear constant and high costs of maintaining the RS, even with its low load. Short deadlines are achieved due to the content of additional human resources [6].

Here is one of the most typical examples from the automotive industry: at the enterprises of GAZ OJSC, two systems for repair work are used in parallel. [7] The first is a system of scheduled preventive repairs; the second is a system for planning repair of equipment according to the results of maintenance with periodic monitoring. The disadvantages of the first system are that the equipment is not modernized, not replaced, and is very expensive for equipment that does not experience constant loading. The disadvantages of the second system are the lack of work to restore worn parts for reuse, which significantly increases the cost of repair work, the use of this system is justified only for equipment that is not used regularly. The disadvantages of one form of organization of repairs are exacerbated by the problems of another, necessitating the introduction of new approaches to organizing the MRO systems in this production complex.

The problems associated with the activities of repair services are also experienced by enterprises of the timber industry complex. Depreciation of fixed assets in most enterprises reaches $60-70 \%$ and the failure of fixed capacities outpaces the commissioning of new equipment. The main problems in this area are the choice of a rational form of management and justification of the feasibility of overhauls. Most researchers [8] propose developing a system of preventive maintenance and building on its basis the organizational structure of the repair service, but since repair service is not the main activity of these enterprises, and the main disadvantage is the lack of a flexible maintenance strategy and forecasting the condition of equipment vain. In such conditions, the best solution would be to find a reliable supplier and to carry out MRO outsourcing.

A high level of repair and maintenance costs has also been identified at mining enterprises [9], where the existing system of repair services is highly costly, low efficiency, and quite labor-intensive. Deficiencies in planning and conducting repair work, as well as imperfection of repair technologies and low quality of spare parts and materials lead to the question of the effectiveness of repair services of these enterprises, and the consequence to the question of improving the organizational structure of internal repair or is it possible to transfer this type of activity outsourcing. 


\section{Weaknesses lead to restructuring}

Outsourcing refers to a number of strategic decisions; this is the refusal of the enterprise to perform not key functions for it, but the transfer of these functions to a third-party contractor. The main results of the application of outsourcing are cost reduction, accordingly, the efficiency of the enterprise, increases the opportunity to free up a number of resources for the development of new areas or focus on existing ones, and allows adapting quickly to the conditions of external graying. The customer company that uses outsourcing gets the opportunity to concentrate on those business processes that are specific to it, on its own specifics.

Outsourcing has the following benefits:

1. Reduction and full control of costs (usually the cost of the services of an outsourcing company is less than the cost of the customer company to perform the same function).

2. Savings on payroll taxes (no longer using your full-time staff).

3. Reduction of staff.

4. Release of internal resources of the customer for other tasks.

5. Customer focus on their core business.

6. Involvement of specialized equipment, knowledge, the technology of an outsourcer company.

7. Minimization of own risks, active use of the competitive factor in the market when choosing an executor.

\section{The nuances of outsourcing}

The analysis carried out by Korovkina [10] revealed the weaknesses of outsourcing and the degree of their influence on the activities of the enterprise; from this analysis, we can conclude that the company will be able to take into account its mistakes and gain a competitive advantage:

1. Outsourcing of only non-core activities.

In order not to lose competitive advantages, an enterprise should not outsource key operations.

2. Reliable organizations with modern technology.

The services provided should not be expensive and innovative.

3. An accurate, complete, balanced and flexible contract.

It is important to form an effective contract.

4. Well-established communications and ethical attitude to staff.

When switching to outsourcing, effective personnel management is of key importance, otherwise, there is a likelihood of losing valuable personnel.

5. Active management of the supplier.

It is important to understand why the transition to outsourcing is taking place; perhaps it makes sense to change this guide to solve problems of enterprise efficiency.

\section{Results}

In the authors' opinion, the transfer of outsourcing maintenance and repair work of the equipment of the parent company should be accompanied by an examination of the following factors:

1. The costs of MRO.

2. Changes in the overhaul period, as a consequence - the productivity of the equipment.

3. Cost of person-hours of MRO. 
4. Qualification level of the repair personnel of an outsourcing company and providing a modern tool.

5. The ability to provide repairs with quality materials and spare parts in full.

6. The ability to switch from a system of scheduled preventive repairs to repairs according to the technical condition of the equipment.

7. Possibilities of structural transformations of the repair service when outsourcing in order to prevent the growth of overhead costs.

Only a thorough study of MRO can give a complete picture of the possibilities of using outsourcing at a machine-building enterprise

\section{Conclusion}

In conditions of increased competition in the market and high wear and tear of equipment, outsourcing can be used to reduce costs and provide quality repairs, and transfer the repair activities of the enterprise to a specialized company. In this case, it is necessary to take into account various factors that can affect the organization of the repair process at the enterprise. It is important to understand that for successful outsourcing it is necessary to use a reliable organization that has modern technology, with which it is possible to conclude a contract that is flexible and beneficial for both parties and whose management will take special responsibility for outsourcing the repair activities at the enterprise.

\section{References}

1. Erokhin E.A., Popov V.N. Reorganization of the system of maintenance and repair of equipment at enterprises // Production Organizer. 2011. No.4.

2. Lobanova G.A., Tikhonova O.V. Improving the organizational structures of the management of services for repair and maintenance of industrial enterprises // Bulletin of the Izhevsk State Technical University. - 2008. - N 4. - p. 78-79.

3. Shakhbanova I. K. Improving the assessment and planning of organizational and technical development of machine-building enterprises // M., Technique, 2009

4. Pichler FB, Turner SJ. The power and pitfalls of outsourcing. Nat Biotechnol. 2007;11:1093-1096; Dick S, Hasson U. Outsourcing neuroimaging data analysis: implications for scientific accountability and issues in the public interest. Trends Cogn Sci. 2010;14:2-4; Bardhan, Ashok Deo, and Cynthia Kroll, 2003. "The New Wave of Outsourcing," Fisher Center for Real Estate and Urban Economics Research Report, UC Berkeley, Fall; Bhagwati, Jagdish, Arvind Panagariya and T. N. Srinivasan, 2004. "The Muddles over Outsourcing," Journal of Economic Perspectives, Volume 18, Number 4, Fall, pp. 93-114; Amiti, Mary, and Shang-Jin Wei, 2005. "Fear of Service Outsourcing: Is it Justified?" Economic Policy, April, pp. 308-348; Amiti, Mary, and Shang-Jin Wei, 2006. "Service Offshoring and Productivity: Evidence from the United States," NBER working paper 11926, January; Blinder, Alan S., 2006. "Offshoring: The Next Industrial Revolution?" Foreign Affairs, March/April.

5. Lutskaya N.V. Outsourcing and insuring as mutually supplementing management tools for forming the optimal organizational structure of enterprises // Production Organizer. 2016. No. 2 (69). p. 41-57; Kuramshina K.S. Small enterprises as an element of production outsourcing in the management of innovative activity of large industrial enterprises // Kazan Science. 2017. No. 5. P. 61-63; Marabaeva L.V., Kuznetsova T.E. Features of outsourcing development in the activities of Russian enterprises // Fundamental and applied research of the cooperative sector of the economy. 2017. No. 1. p. 49-55; Nikitin V.V. Outsourcing as a tool for increasing competitiveness of the enterprise // Bulletin of scientific conferences. 2017. No. 3-5 (19). p. 128-130; Alkaravi 
H.D.V. Modern classification of outsourcing at the enterprise // Bulletin of the Chelyabinsk State University. 2018.No 3 (413). p. 110-117; Sinyaev V.V. Development of the organizational mechanism of outsourcing at the enterprise of mechanical engineering // Economics and Management in Mechanical Engineering. 2018. No. 4. P. 14-16; Kulembaeva F.M. Outsourcing as an instrument of increasing efficiency of the enterprise // Statistics, accounting and audit. 2018. No. 4 (71). p. 135-140

6. Volkova M.V., Volkova T.I., Kuznetsov A.S., Rykova Y.S., Mamedova V.A., Polishchuk M.I. Reorganization of the repair facilities of an industrial enterprise and assessment of its feasibility // Scientific Review. - 2015 - No. 22. - p.419-424

7. Adyan S.I. Analysis of repair management systems at machine-building enterprises (for example, GAZ OJSC) // Dokl. USSR Academy of Sciences. 1975.Vol. 241, No. 4. p. 745 748.

8. Kiryukhina O.I. Planning and organization of the maintenance and repair of a competitive forestry enterprise // Problems of the modern economy. 2009. No4 (32). p 118-120.

9. Andreeva L. I., Krasnikova T. I., Ushakov Yu. Yu. Methodology for the formation of an effective system for ensuring the operability of mining equipment // Izvestiya Vysshikh Uchebnykh Zavedenii. 2019.No 5. p. 92-106.

10. 1Korovkina Natalya Ivanovna Problems and prospects of using outsourcing // Bulletin of the TulSU. Economic and legal sciences. 2018. №1-1. 